\title{
Gas Sensing Properties of Carbon Nanotubes Modified with Calixarene Molecules Measured by QCM Techniques
}

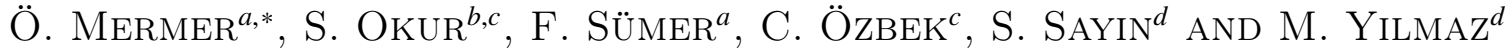 \\ ${ }^{a}$ Department of Electrical and Electronics Engineering, Ege University, 35100, İzmir, Turkey \\ ${ }^{b}$ Department of Phyiscs, Faculty of Sciences, İzmir Institute of Technology, 35430, İzmir, Turkey \\ ${ }^{c}$ Department of Metallurgy, İzmir Katip Çelebi University, İzmir, Turkey \\ ${ }^{d}$ Department of Chemistry, Selcuk University, Konya, Turkey
}

\begin{abstract}
This study focuses on the characterization and optimization of calixarene modified carbon nanotube thin films for gas detection. Calixarene molecules were synthesized individually by considering their functional groups to attract the gas. Calixarene modified carbon nanotube based sensors were fabricated using drop-casting method on a quartz crystal microbalance gold electrode. Carbon monoxide, carbondioxide, oxygen and dry air were used as active gases for adsorption process, while high-purity nitrogen gas was used for desorption process. The selectivity and sensitivity of calixarene modified carbon nanotube are investigated in detail. Our experimental results show that functional calixarene modified carbon nanotube coated quartz crystal microbalance sensors are very sensitive and selective to gas of $\mathrm{CO}_{2}$ at room temperature operation.
\end{abstract}

PACS: 66.30.je, 65.40.gp, 65.40.gk, 65.40.gd, 64.70.fm, 64.10. $+\mathrm{h}, 51.10 .+\mathrm{y}$

\section{Introduction}

Carbon dioxide $\left(\mathrm{CO}_{2}\right)$ is an odorless, colorless, non-flammable gas that is natural product of cellular respiration and burning of fossil fuels. It is also one of the major greenhouse gases. Normal concentration in atmosphere is about $0.039 \%$. Carbon dioxide becomes toxic for human at higher concentrations, 1\% (10000 ppm) may cause feeling drowsy, higher concentrations may cause dizziness, headache, visual and hearing dysfunction and unconsciousness [1]. $\mathrm{CO}_{2}$ entering body by respiration may cause an acidosis environment in blood by the chemical reaction

$$
\mathrm{CO}_{2}+\mathrm{H}_{2} \mathrm{O} \leftrightarrow \mathrm{H}_{2} \mathrm{CO}_{3} \leftrightarrow \mathrm{H}^{+}+\mathrm{HCO}^{3-} .
$$

The product of this chemical reaction is hydrogen ions $\left(\mathrm{H}^{+}\right)$and bicarbonate $\left(\mathrm{HCO}^{3-}\right)$. Exposing to higher concentration for long times causes high amount of hydrogen ions that cause an acidic-base imbalance in blood and $\mathrm{pH}$ of blood becomes less than 7.35 [2].

Calixarenes are cyclic oligomers that can be easily functionalized from their upper and lower rims. The cylindrical shaped calixarenes of varying cavity sizes can form a variety of host-guest types of inclusion complexes. This feature of calixarene is similar to cyclodextrins. However, $\pi-\pi$ interaction is observed in calixarenes due to

\footnotetext{
* corresponding author
}

the benzene groups [3]. Thin calixarene films have been produced via several techniques including drop casting, self-assembly, the Langmuir-Blodgett (LB), and spin-coating [4-7]. The functional groups at the upper and lower rims determine their selectivity in host-guest interactions and physical properties $[6,7]$. Due to their zeolite-like capacity and selectivity and also simplicity of producing thin films, calixarenes became promising materials for gas sensor applications especially in detecting $\mathrm{NO}_{2}, \mathrm{CO}_{2}, \mathrm{CO}$, volatile and humidity gases [8-13].

Quartz crystal microbalance (QCM) is a powerful technique for determining the sorption properties of materials with respect to the specific gas. The fundamental principle of QCM was first explained by Sauerbrey in 1959 [14]. The mass change $(\Delta m)$ on surface of the quartz crystal is calculated by using the Sauerbrey equation [14] from the frequency change $(\Delta f)$ :

$$
\Delta f=-\frac{2 f_{0}^{2}}{A \sqrt{\rho \mu}} \Delta m=-C \Delta m,
$$

where $f$ is the resonant frequency of the fundamental mode of the QCM crystal, $A$ is the area of the gold disk coated onto the crystal, $\rho$ is the density of the crystal, and $\mu$ is the shear modulus of quartz. Hence the frequency shift is directly proportional to the adsorbed mass on the calixarene modified gold QCM electrodes by a constant value of $C$. Because of its high reliability and stability, low cost and low power requirement, ease of surface coating, and nanogram scale sensivity, QCM 
technique has increased interest both in liquid and gas phase applications.

\section{Experimental}

\subsection{Synthesis of calix/4]arenes}

p-tert-butylcalix[4]arene,5,11,17,23-tetra-tert-butyl-25,27-dicarboxylmethoxy-26,28-dihydroxycalix[4]arene were synthesized according to previously described procedures $[15,16]$. In this study, this calixarene was selected as base molecule and named as calix1. In order to investigate selectivity and sensitivity properties of materials to the different gases, base calixarene molecule (calix 1) was functionalized by adding different upper and lower rims and various molecules synthesized were named as calix 2, calix 6 and calix 11, respectively. Molecular structures of base molecule and its derivatives are given in Fig. 1 with detailed chemical names.

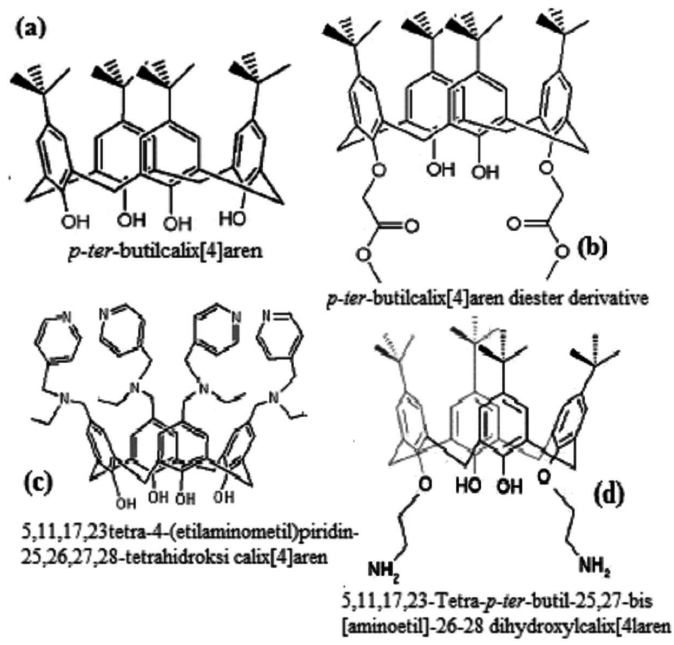

Fig. 1. Molecular structures with detailed chemical names of (a) calix 1, (b) calix 2, (c) calix 6, and (d) calix 11.

\subsection{Modification of carbon nanotubesCNTs and preparation of films}

$\mathrm{COOH}$ functionalized single wall carbon nanotubes (CNTs) (SWCNT-COOH) with the purity of $90 \%$, outer diameter of $1-2 \mathrm{~nm}$ and $5-30 \mu \mathrm{m}$ long were obtained from Cheaptubes Inc. Calixarene modified SWCNT-COOH molecules have been prepared by following steps: $1 \mathrm{mM}$ calixarene solutions were ultrasonicated for $1 \mathrm{~h}$ to solve completely calix[4]arene molecules in chloroform $\left(\mathrm{CHCl}_{3}\right)$. SWCNT-COOH structures were then added into each perfectly solved calix[4]arene solution and $12 \mathrm{~h}$ ultrasonication process was applied into these mixture of solutions. Long ultrasonication process also mechanically allows cutting off long CNT structure and opening their ends. Finally, solutions were kept in room temperature for $48 \mathrm{~h}$.
Gold coated quartz crystal electrodes were ultrasonically cleaned in acetone, ethanol and 2-propanol liquids, respectively, and then dried with high purity nitrogen. Drop casting method has been applied on gold surface of crystal electrodes by dropping $5 \mu \mathrm{l}$ calixarene modified SWCNT-COOH solution and the electrodes heated to $60^{\circ} \mathrm{C}$ for $10 \mathrm{~min}$.

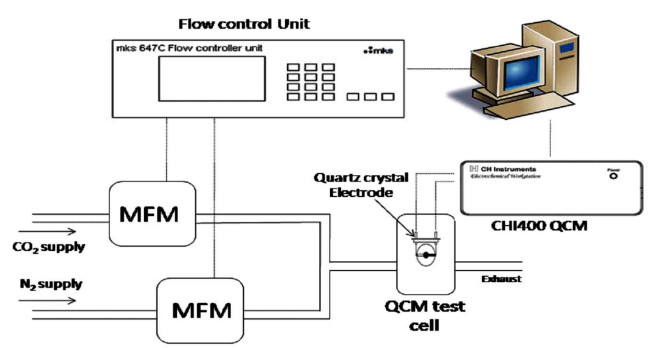

Fig. 2. An experimental QCM setup of calixarene modified CNT films under different gases.

Adsorption and desorption of calixarene modified CNT films were investigated under exposure of various gases such as $\mathrm{CO}, \mathrm{CO}_{2}, \mathrm{O}_{2}$, and dried air. Experimental setup is shown in Fig. 2 including home-made 2-channel gas flow system with necessary software and equipments. The QCM works with oscillation frequencies between $7.995 \mathrm{MHz}$ and $7.950 \mathrm{MHz}$. AT-cut quartz crystals with a fundamental frequency of $7.995 \mathrm{MHz}$ were obtained from International Crystal Manufacturing Co. (ICM). The density $(\rho)$ of the crystal is $2.684 \mathrm{~g} / \mathrm{cm}^{3}$ and the shear modulus $(\mu)$ of quartz is $2.947 \times 10^{11} \mathrm{~g} / \mathrm{cm} \mathrm{s}^{2}$. Around oscillation frequency, a net change of $1 \mathrm{~Hz}$ corresponds to $1.34 \mathrm{ng}$ of gas molecules adsorbed or desorbed onto the crystal surface of an area of $0.196 \mathrm{~cm}^{2}$.

\section{Results and discussion}

Figure 3 shows SEM images of the calix 1 modified CNT deposited on Si substrates for different zoom factors. It can be seen that the CNT surfaces were smooth and calix 1 molecules interacted with these surfaces and their surface became rough.

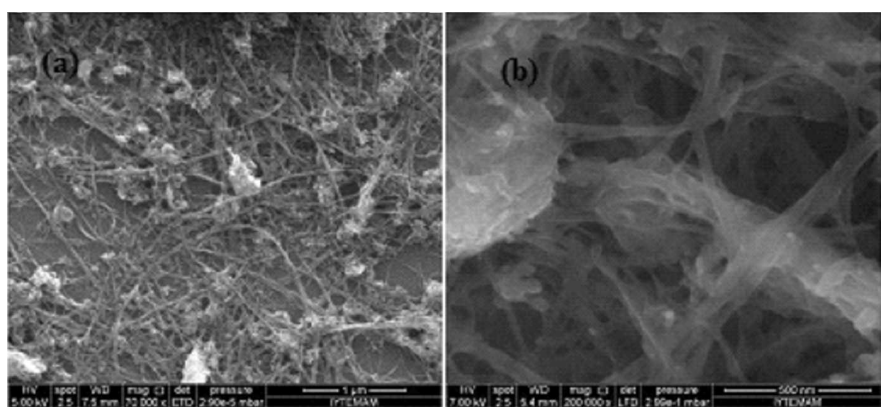

Fig. 3. SEM images of calix[4]arene modified SWCNT- $\mathrm{COOH}$ structures. 


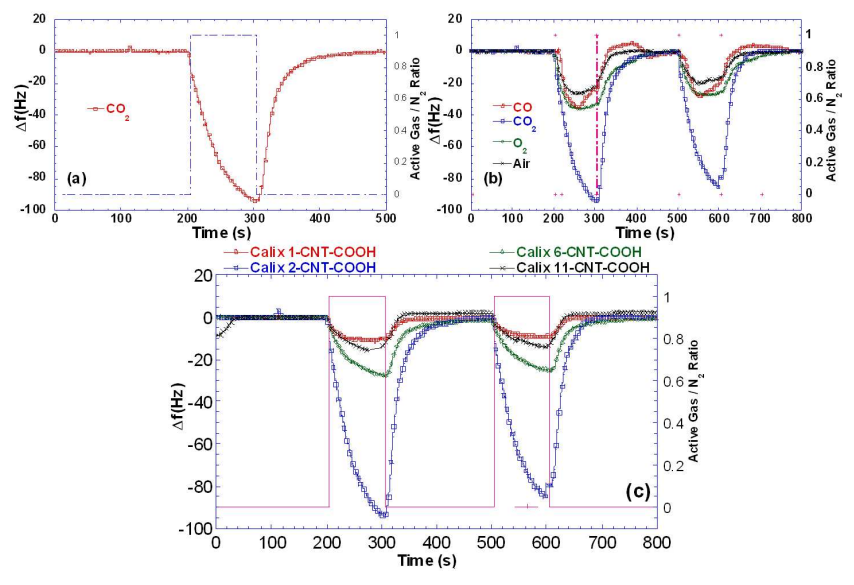

Fig. 4. QCM frequency shift of: (a) calix 2 modified CNT films for adsorption and desorption cycles under $\mathrm{CO}_{2}$, (b) calix 2 modified CNT film under different gases, (c) various calixarene molecules modified CNT films under $\mathrm{CO}_{2}$.

Figure 4a shows the frequency response of calix 2 modified CNT film coated on the QCM electrode during adsorption process under $\mathrm{CO}_{2}$. In order to investigate gas selectivity properties of these modified CNT film, measurements were done under different gases and result is shown in Fig. 4b. All the experiments were done in the same conditions. It is seen that calix 2 modified CNT film has very large response for $\mathrm{CO}_{2}$ with respect to the other gases. To determine the sensitivity properties of these films, CNTs were modified with the various calixarene molecules synthesized and coated on the QCM electrodes and measured under $\mathrm{CO}_{2}$ in the same conditions. Data is shown in Fig. 4c. The response of calix 2 modified CNT films has larger effect than the others. In addition, all the measurements show no hysteresis after the gas adsorption and desorption process.

\section{Conclusions}

Calix[4]arene modified CNT films based sensors were fabricated using drop-casting method on a QCM gold electrode. $\mathrm{CO}_{2}, \mathrm{CO}, \mathrm{O}_{2}$ and dry air were used for adsorption process, while nitrogen was used for desorption process. Selectivity and sensitivity properties of these films were investigated successfully. Our QCM results show that functional calix2 modified CNT coated QCM sensors are very sensitive and selective to $\mathrm{CO}_{2}$ at room temperature.

\section{Acknowledgments}

This research was supported by Tubitak (Turkish Scientific Association) under project numbers TBAG 109 T240 and 110 M349 and IYTE research project number 2010IYYTE25.

\section{References}

[1] Toxicity of Carbon Dioxide Gas Exposure, $\mathrm{CO}_{2}$ Poisoning Symptoms, Carbon Dioxide Exposure Limits, and links to Toxic Gas Testing Procedures, Daniel Friedman, InspectAPedia.

[2] S.K. Epstein, N. Singh, Respir. Care 46, 366 (2001).

[3] S. Sasaki, S. Aisawa, H. Hirahara, A. Sasaki, H. Nakayama, E. Narita, J. Eur. Ceram. Soc. 26, 655 (2006).

[4] F. Perret, A.N. Lazar, A.W. Coleman, Chem. Commun., 2425 (2006).

[5] K. Suga, T. Ohzono, M. Negishi, K. Deuchi, Supramol. Sci. 5, 9 (1998).

[6] S.I. Ohira, E. Wanigasekara, D.M. Rudkevich, P.K. Dasgupta, Talanta 77, 1814 (2009).

[7] M. Tabakci, B. Tabakci, M. Yilmaz, J. Incl. Phenom. Macrocycl. Chem. 53, 51 (2005).

[8] S. Okur, M. Kus, F. Ozel, M. Yilmaz, Sensors Actuators B Chem. 145, 93 (2010).

[9] S. Okur, M. Kus, F. Ozel, V. Aybek, M. Yilmaz, Talanta 81, 248 (2010).

[10] I.A. Koshets, Z.I. Kazantseva, Yu.M. Shirshov, S.A. Cherenok, V.I. Kalchenko, Sensors Actuators B 106, 177 (2005).

[11] D. Filenko, T. Gotszalk, Z. Kazantseva, O. Rabinovych, I. Koshets, Yu. Shirshov, V. Kalchenko, I.W. Rangelow, Sensors Actuators B 111-112, 264 (2005).

[12] T.H. Richardson, R.A. Brook, F. Davis, C.A. Hunter, Coll. Surf. A, Physicochem. Eng. Aspects 284-285, 320 (2006).

[13] D. Filenko, Z. Kazantseva, K. Ivanova, O. Rabinovych, A. Kukla, Y. Shirshov, V.I. Kalchenko, I.W. Rangelow, in: Proc. IEEE Sensors 2004 Conf., Vienna (Austria), Eds. D. Rocha, P.M. Sarro, M.J. Vellekoop, Vienna, Austria, 2004. 2004 p. 669.

[14] G. Sauerbrey, Z. Phys. 155, 206 (1959).

[15] C.D. Gutsche, M. Iqbal, D. Stewart, J. Org. Chem. 51, 742 (1986).

[16] E.M. Collins, M.A. McKervey, E. Madigan, M.B. Moran, M. Owens, G. Ferguson, S.J. Harris, J. Chem. Soc., Perkin Trans. 1, 3137 (1991). 